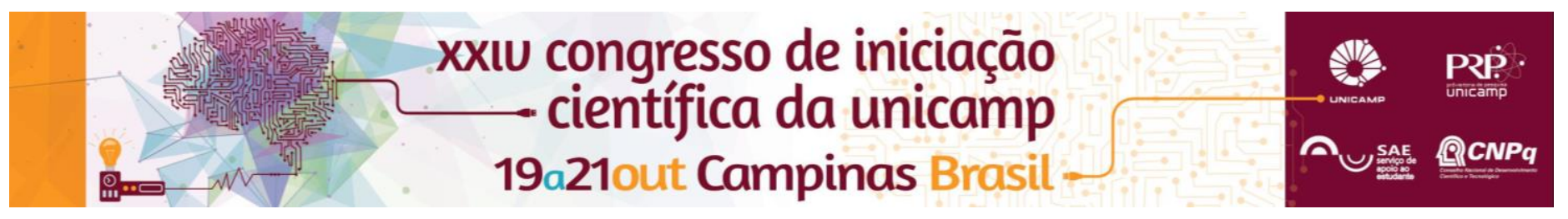

\title{
Conhecimento de mães sobre a Síndrome da Morte Súbita do Lactente.
}

\author{
Juliana Benine Warlet Rocha* (IC), Mariana Gabriela Anselmo (PG), Rosana de Fátima Possobon (PQ)
}

\section{Resumo}

Esse estudo visa investigar o conhecimento das mães sobre a Síndrome da Morte Súbita do Lactente, que é definida como a morte de qualquer lactente com menos de um ano de idade por causas desconhecidas mesmo após a investigação completa do caso. A maioria das mães $(70 \%)$ alegou já ter ouvido falar da SMSL, sendo que aquelas que não conheciam tiveram 6,23 vezes mais chance de errar a definição da Síndrome. As mães que apresentavam menor grau de instrução $(p=0,0004)$ e menor renda mensal familiar $(p=0,0003)$ tinham mais chance de errar a definição da SMSL.

\section{Palavras-chave:}

Morte Súbita, Lactente, Morte Súbita do Lactente.

\section{Introdução}

A Síndrome da Morte Súbita do Lactente (SMSL) é caracterizada pela morte de lactentes com idade inferior a um ano de idade, sem causa conhecida, mesmo após o estudo minucioso do caso clínico, análise do local onde o óbito ocorreu e exames post mortem completos. Vários mecanismos fisiopatológicos têm sido elencados como fatores de risco para a ocorrência da SMSL sendo que a mais significativa é a posição de dormir em decúbito ventral (posição prona). O objetivo do estudo é investigar se mães de crianças com até 12 meses de idade sabem o que significa a SMSL, uma vez que a vivência clínica tem mostrado que as mães não sabem sobre a existência ou importância da Síndrome e, tampouco, conhecem as formas de prevenção.

\section{Resultados e Discussão}

Foram coletados dados socioeconômicos, demográficos e sobre a SMSL junto a 100 mães, maiores de 18 anos e com filhos com idade inferior a 12 meses. Perguntava-se à mãe se ela já tinha ouvido falar da Síndrome da Morte Súbita do Lactente e se ela sabia o que era esta Síndrome. Ela deveria escolher entre 5 alternativas possíveis, sendo que apenas uma era a verdadeira. A maioria das mães $(70 \%)$ alegou já ter ouvido falar da SMSL, sendo que aquelas que não conheciam tiveram 6,23 vezes mais chance de errar a definição da Síndrome. As mães que apresentavam menor grau de instrução $(p=0,0004)$ e menor renda mensal familiar $(p=0,0003)$ tinham mais chance de errar a definição da SMSL. Não houve associação entre idade da mãe e o erro/acerto da questão (Tabela 1).

Atribui-se à falha no diagnóstico da Síndrome da Morte Súbita do Lactente em território Nacional, principalmente devido à ausência de todas as informações necessárias para realizá-lo de forma adequada durante a necropsia, à maior dificuldade em contabilizar a Síndrome de forma correta, subestimando a importância desta ocorrência à sociedade e aos profissionais de saúde, o que desestimula a condução de campanhas informativas.
Tabela 1. Associação entre fatores socioeconômicos e demográficos maternos e a definição da Síndrome da Morte Súbita do Lactente. Piracicaba, SP, 2015.

\begin{tabular}{|c|c|c|c|c|c|c|c|}
\hline \multirow[b]{2}{*}{ Varíável } & \multicolumn{7}{|c|}{ Definição da SMSL } \\
\hline & Categoria & $\mathbf{N}$ & Acerto & Erro & OR & IC $(95 \%)$ & $\mathbf{p}$ \\
\hline \multirow{2}{*}{$\begin{array}{l}\text { Idade } \\
\text { Materna }\end{array}$} & $\leq 33$ & $57(57 \%)$ & $32(56,14 \%)$ & $25(43,86 \%)$ & 2,01 & $0,86-4,70$ & 0,1537 \\
\hline & $>33$ & $43(43 \%)$ & $31(72,09 \%)$ & $12(27,91 \%)$ & 1,00 & & \\
\hline \multirow{2}{*}{$\begin{array}{l}\text { Grau de } \\
\text { Instrução }\end{array}$} & $\begin{array}{l}\leq \text { Superior } \\
\text { Incompleto }\end{array}$ & $57(57 \%)$ & $27(47,36 \%)$ & $30(52,64 \%)$ & 5,71 & $2,18-14,95$ & 0,0004 \\
\hline & $\begin{array}{c}\text { Superior } \\
\text { Completo }\end{array}$ & $43(43 \%)$ & $36(83,72 \%)$ & $7(16,28 \%)$ & 1,00 & & \\
\hline \multirow{2}{*}{$\begin{array}{c}\text { Renda } \\
\text { Familiar }\end{array}$} & $\begin{array}{c}\leq 4 \text { salários } \\
\text { mínimos }\end{array}$ & $62(62 \%)$ & $30(48,38 \%)$ & $32(51,62 \%)$ & 7,04 & $2,42-20,40$ & 0,0003 \\
\hline & $\begin{array}{c}>\text { de } 4 \text { salários } \\
\text { mínimos }\end{array}$ & $38(38 \%)$ & $33(86,84 \%)$ & $5(13,16 \%)$ & 1,00 & & \\
\hline \multirow{2}{*}{$\begin{array}{c}\text { Ouviu } \\
\text { falar da } \\
\text { SMSL }\end{array}$} & Sim & $70(70 \%)$ & $53(75,71 \%)$ & $17(24,29 \%)$ & 1,00 & & \\
\hline & Não & $30(30 \%)$ & $10(33,34 \%)$ & $20(66,66 \%)$ & 6,23 & $2,44-15,88$ & 0,0001 \\
\hline
\end{tabular}

\section{Conclusões}

Embora muitas mães já tenham ouvido falar sobre a SMSL, ainda há uma parcela considerável que não tem informações a respeito e, portanto, não devem estar realizando as práticas para prevenção da Síndrome com seus filhos, expondo-os ao risco.

\section{Agradecimentos}

À PIBIC-CNPq pela concessão da bolsa de Iniciação Científica.

Nunes ML, Pinho APS, Aerts D, Sant' Anna A, Martins MPM, Costa JC. Síndrome da morte súbita do lactente:aspectos clínicos de uma doença subdiagnosticada. J Pediatr. 2001; 77: 29-34.

Pinho APS, Aerts D, Nunes ML. Fatores de risco para síndrome da morte súbita do lactente em um país em desenvolvimento.Rev Saúde Pública. 2008; 42: 396-401.

Geib LTC, Aerts D, Nunes ML. Sleep Practices an Sudden Infant Death Syndrome: A New Proposal for Scoring Risk Factors.Sleep. 2006:29; 12881294. 